\title{
Correction to: The Fossil Fuel Bugbear of Climate Change-A Perspective
}

\section{Correction to:}

Chapter 6 in: R. Sharma and V. Pareek, The World

of Energy, https://doi.org/10.1007/978-981-15-6724-7_6

The original version of this chapter was revised: Following correction has been incorporated in Figure 6.1. All points on horizontal axis scale in Figure 6.1 were all erroneously shown as ' 600 '. They should be read as 600, 500, 400, 300, 200, 100, 0 .

The updated version of this chapter can be found at https://doi.org/10.1007/978-981-15-6724-7_6 